\title{
Transient Responses of Rabbit Retinal Ganglion Cells to Photic and Electrical Stimuli
}

\author{
S. MOLOTCHNIKOFF
}

SUMMARY - The relarionships between the center and the surround of the receptive field of the rabbit retinal ganglion cell were investigated. This was done by coupling localized light spots and electrical activation of the retina and by analyzing the time of the excitatory and inhibitory periods. The responsiveness to the electrical transretinal pulse revealed a) that $O N$ stimulation in OFF-center cells and $O F F$ stimulation in $O N$-center cells, elicited a primary period of inhibition with a short latency; b) the long latency response of surround stimulation was not preceded by an inhibitory period unless the center was simultaneously stimulated in the same direction; c) a transient response to a stationary spot of light is followed by a period of inhibition. These results are discussed in relation to the known cellular retinal networks.

RÉSUMÉ - Les relations entre le centre et la périphérie du champ récepteur des cellules ganglionnaires rétiniennes furent étudiées à l'aide d'un protocole expérimental utilisant la stimulation électrique de la rétine ainsi que la stimulation photique localisée. Les variations de responsivité des cellules ganglionnaires à la stimulation électrique de la rétine ont montré que a) les stimulations $O N$ des cellules à centre OFF et les stimulations OFF des cellules à centre $O N$ produisent une période d'inhibition de courte latence. b) La réponse à longue latence à la suite d'une stimulation de la périphérie n'est pas précédée d'une phase inhibitrice, sauf si le centre est aussi activé simultanément c) La réponse phasique est toujours suivie d'une période inhibitrice. Ces résultats sont rattachés au réseau cellulaire rétinien.

From the Département de Sciences biologiques, Université de Montréal Qué., Canada.

Reprint requests to Professor S. Molotchnikoff Department de Sciences biologiques, Université de Montréal, Case postal 6128, Montréal 101, Canada

\section{INTRODUCTION}

A single optic nerve fiber responds to a light stimulus - bright or dark - only if a precise region of the visual field is invaded by the stimulus. This region has been termed the receptive field (Kuffler, 1953). The predominant organization of a receptive field of a retinal ganglion cell is concentric with a center and a surround. Functionally, the relationships between these two regions are mutually antagonistic. In line with Kuffler's (1953) and Fukada's (1971) findings, most of the receptive fields may be classified into two groups: ON-center and OFF-center. In rabbits, over $50 \%$ of retinal ganglion cells may also be classified as ON- or OFF-center cells (Barlow et al., 1964). This classification is based upon the location of the most effective stimulus. Thus, in ON-center units, only the brightening of the center will evoke a discharge of the ganglion cell, whereas a dimming stimulus will be excitatory only in the surround. A converse situation holds for OFF-center cells. The antagonistic interactions between the center and the surround have been evidenced (Kuffler, 1953; Rodieck, 1965; Enroth-Cugell and Pinto, 1972a, b, 1970 and Barlow et al., 1964) by the reduction of the ganglion cell discharges when the two areas were excited simultaneously. It is these inhibitory interactions which are further studied in the present paper.

Numerous investigators (Barlow, 1953; Rodieck, 1965; Rodieck and Stone, 1965) have analyzed these antagonistic properties using a timeaveraging computer. They have studied the variations in firing rate of ganglion cells in response to localized stimuli. It was concluded that specific areas give rise to predominantly inhibitory or excitatory pathways to a given ganglion cell (Enroth-Cagell and Pinto, 1972a et b).

The aim of the present study is to analyze these excitatory and inhibitory pathways underlying receptive field organization. The method used, pairs electrical stimulation of the retina (Allan, 1969; Crapper and Noell, 1963 and Molotchnikoff, 1972) with photic stimuli. The responses to trans-retinal electrical stimuli have already been extensively described by Crapper and Noell (1963). These studies were mainly concerned with the responses of the large ganglion cell population of rabbit retina, i.e. the F-cells, which represent a uniform population of large field, OFF-center cells (Lederman and Noell, 1969-1968). These authors demonstrated that on electrical stimulation of the retina, the F-cells became alternately inhibited and excited. The sequences of inhibitory and excitatory pauses depend upon the direction of the current. The question asked in the present paper is: how does this excitation and inhibition interact with the activity of a ganglion cell? The responsiveness of ganglion units to electrical activation of the retina is tested before and after a transient firing in response to a light spot turned ON or OFF positioned within the center and/or surround of the receptive field.

\section{METHOD}

\section{Preparation}

Albino rabbits $(2.5-3.5 \mathrm{~kg})$ used in this study were anesthetized with an intravenous injection of $0.8 \mathrm{~g} / \mathrm{kg}$ of Urethane in $25 \%$ saline solution, and paralyzed with $5 \mathrm{mg} / \mathrm{kg}$ of Gallamine triethiodide which was dis- 
solved in $.9 \%$ saline and given I.V at a rate of $1 \mathrm{ml} / \mathrm{hr}$. The rabbits were artificially ventilated and fixed in a modified stereotaxic apparatus which did not obstruct the visual field. In order to minimize the movement of the brain created by respiration and pulse the spinal fluid was drained. A $3 \%$ agar solution was poured on the cortical surface which formed a thin layer between the cortical surface and the skull. A contact lens was placed over the cornea to correct the rabbit's usual hypermetropia and to prevent the cornea from drying and clouding.

\section{Stimulation}

Two modes of stimulation were used, electrical and photic. A short (.5 to $1 \mathrm{msec}$ ) electrical pulse across the retina was applied between an active platinum electrode positioned in the anterior chamber of the eye and a reference electrode placed in the soft tissue behind the globe. Special care was exercised to avoid obstructing the pupil opening. The direction of the current was defined in reference to the polarity of the corneal electrode. An anodal pulse (AS) means that the corneal electrode was linked to the positive pole of the stimulator, hence the current was in the vitreous-scleral direction.

Alternatively, a corneal electrode connected to the negative pole of the stimulator defined a cathodal pulse (CS) with the current flowing in the scleral-vitreous direction. This mode of transretinal stimulation was used as a test stimulus.

The method for mapping the receptive field was similar to that used by Barlow et al., (1964); Barlow and Levick, (1965); and Levick, (1967). Once an optic fiber was isolated, its receptive field was located on an adjustable mirror placed in front of the eye and projected onto a translucent screen, at a distance of $57 \mathrm{~cm}$ from the eye. The center and surround of the field were mapped with a spot of light $.5^{\circ}$ to $1^{\circ}$ in diameter shone onto the screen, and turned $O N$ and OFF. In this paper the receptive field is that part of the visual field which when stimulated by a small spot of light turned $\mathrm{ON}$ or OFF produced a change in the cell activity. The screen subtended an angle of $27^{\circ}$. In all experiments the unattenuated intensity of the light projecting onto the screen was $15 \mathrm{~F}$. C. During the mapping of the receptive fields the spots presented upon the center and/or surround had a luminance of $2 \log$ units above the threshold, against a dark background $(0.3 \mathrm{mil}-$ lilamberts) which was kept constant throughout the experiments.

The following notations indicate the kind and location of the stimuli used in this paper. B and D denote brightening step changes in luminosity, i.e. light $\mathrm{ON}$, and dimming step, i.e. light OFF, respectively. Subscripts $\mathrm{c}$ and $\mathrm{s}$ denote the location of the step; c: spot is applied to the center of the receptive field, s: spot is applied to the most responsive area of the surround. Subscript d denotes a uniform or diffuse application of the stimulus which covers the receptive field entirely. AS and CS indicate the electrical stimulation of the retina: anodal and cathodal respectively. The abbreviation $R$. F. stands for receptive field.

The activity of the optic nerve axons was recorded with a tungsten microelectrode sharpened in a saturated $\mathrm{KOH}$ solution. The microelectrode with an impedance of $1 . \mathrm{M} \Omega$, measured at $1 \mathrm{Khz}$, was lowered stereotaxically, the approach to the fibers being monitored by a loudspeaker. The axon activity was amplified and recorded on a cathode ray oscilloscope and photographed for subsequent analysis. A spike dis-

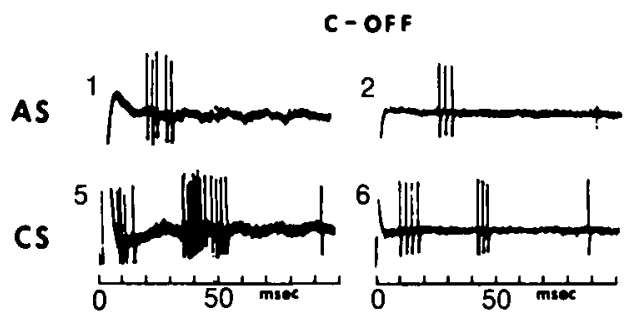

criminator was also available to isolate the activity of a single fiber, should the electrode record from more than one axon simultaneously.

\section{RESULTS}

\section{A) Responses to transretinal} electrical pulses

Fig. 1 illustrates three examples of a typical pattern of firing of two OFF-center cells and ON-center cells in response to electrical transretinal stimuli. The cells were classified as OFF-and ON-center cells according to the organization of the receptive field as determined by mapping procedures described in the methods. In OFF-center cells the anodal pulse (AS) evoked one distinct burst with a latency of 18 to 26 msec (Fig. 1, $1 \&$ 2). The most important feature of this response was the appearance of silent periods, one before the burst and one after. These have been shown to be inhibitory (Allen, 1969). The reversal of the polarity (CS) (Fig. 1, $5 \& 6$ ), without changing the current strength, elicited two bursts: the first with a short latency of $10 \mathrm{msec}$ or less; the second with a longer latency of about $40 \mathrm{msec}$. In ONcenter units, the pattern of firing was reversed, the anodal pulse evoked a short latency burst (Fig. 1, $3 \&$ 4) while a cathodal pulse evoked a long latency one (Fig. 1, $7 \& 8$ ). Since in OFF-center cells, the responses to light OFF had a shorter latency than the responses to light $\mathrm{ON}$, and conversely, in ON-center units it is the

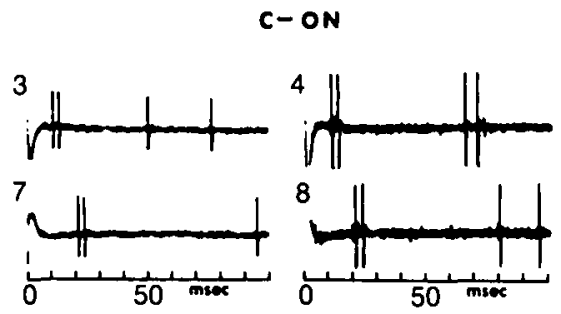

Figure I - Latencies of responses of two different OFF-center (C-OFF) and Oncenter (C-ON) ganglion units following electrical stimulation of the retina. Upper tracings: responses to anodal transretinal pulse (AS). Single bursts of long latency in OFF-center units tracing 1,2. The bursts are of short latency in ON-center cells tracings 3,4. Lower tracings responses to cathodal pulse (CS). The current strength is the same as for the corresponding anodal pulse. Two bursts are elicited in OFFcenter units. The first having a $10 \mathrm{msec}$ latency, the second a $40 \mathrm{msec}$ latency in OFF-center units, tracings 5,6. In ON-center units one burst of long latency, tracings 7,8 . 
ON response which appeared with a shorter latency (Barlow et al., 1965; Molotchnikoff, 1972) it seemed that the electrical activation of the retina mimics the effect of the light. This appears true to the extent that the response to the electrical pulse will present a discharge and its latency will depend upon the receptive field type. These differences were so consistent that it was possible to predict the center-type of the unit by comparing the ON-and OFFlatencies to diffuse light. Hence, the short latency excitation and the long latency excitation may be distinguished.

The analysis of the present study required coupling of the electrical stimulus with localized spot stimuli evoking responses to either brightening or dimming. both within the receptive field centers or in the surround. A reduction in responsiveness to transretinal pulses was considered to be indicative of an inhibitory process. The coupling was selected in such a way that the bursting activity elicited by a transretinal electrical pulse coincided with selected periods following "ON" or "OFF" light stimuli. Cathodal or anodal stimuli used for testing were chosen depending upon which stimulus elicited most consistently a burst of 2 to 4 impulses and which of the bursts was most appropriate for testing with respect to the pattern of impulse activity elicited by brightening or dimming.

\section{B) Inhibition from non-excitatory stimuli in the center of an OFF-center unit}

Fig. 2 illustrates changes in the transretinal responses which follow increase of intensity of a centered spot, i.e. the non-excitatory stimulus of an OFF-center unit. Fig. 2-A, top tracing AS, shows the control response to an anodal transretinal stimulating pulse. Three spikes were evoked with a long latency (mean: $2.7, \mathrm{SD} \pm 0.34 \mathrm{n}=50$ ). Fig. 2,1 illustrates the "OFF" discharge evoked by turning light OFF or a dimming step of the spot positioned in the center. Tracing 2 (Fig. 2) shows that the opposite stimulus, i.e. brightening the center does not evoke any impulse activity indicating that the spot was restricted to the center, and was not encroaching upon the surround. In the following tracings (Fig. 2, 3 to 8) anodal transretinal pulses were delivered at various times following light " $\mathrm{ON}$ ". This resulted in a striking reduction in the responsiveness to the anodal pulse. Thus, $50 \mathrm{msec}$ after the "ON" of the light, only one electrically evoked spike remained (Fig. $2,3)$. The transretinal electrical pulse failed to evoke any spike, from 55 (Fig. 2, 4, 5, 6) to about $100 \mathrm{msec}$, when 2 or 4 impulses occurred again, thus indicating the moment at which the inhibitory effect terminated (Fig. $2,7,8$ ). Trace 9 of Fig. 2 shows that the release of inhibition coincided approximately with the occurrence of the "ON" discharge evoked by diffuse brightening $(\mathrm{Bd})$.

Hence, spot brightening or turned ON in the center of an OFF-center cell produced a transient period of decreased excitability of the unit, i.e. an inhibitory period, which occurred 40 to $50 \mathrm{msec}$ after brightening.

\section{C) Inhibition from non-excitatory stimuli in the center of an ON-center unit}

Fig. 3 shows a similar experimental procedure to that of Figure 2 but with an ON-center unit. The time course of inhibition was determined following dimming stimulus or light OFF of the central spot. The top tracing (CS) shows a control cathodal transretinal pulse: 4 spikes were evoked $($ mean $=2.2, \mathrm{SD} \pm$ 0.54 ). Figure 3,1 shows the response to light ON. That the central core of the receptive field was exclusively activated is shown in tracing 2 (Fig. 3). It can be seen that the OFF stimulus did not evoke excitatory activity. The next tracings (Fig. 3, 3 to 7) illustrate the alteration of responsiveness to the transretinal cathodal pulse at various moments following the dimming stimulus. It can be seen that the number of spikes was reduced to one, $45 \mathrm{msec}$ after the light dims. This reduction in spike number lasted up to 180 msec after the onset of the dimming stimulus (Fig. 3, 7). Hence, this re- duction by the dimming of light OFF stimulus of the cathodal discharge reveals that an inhibitory process had developed since it opposed the response evoked by a cathodal pulse. This inhibition was not complete since one spike was always seen.

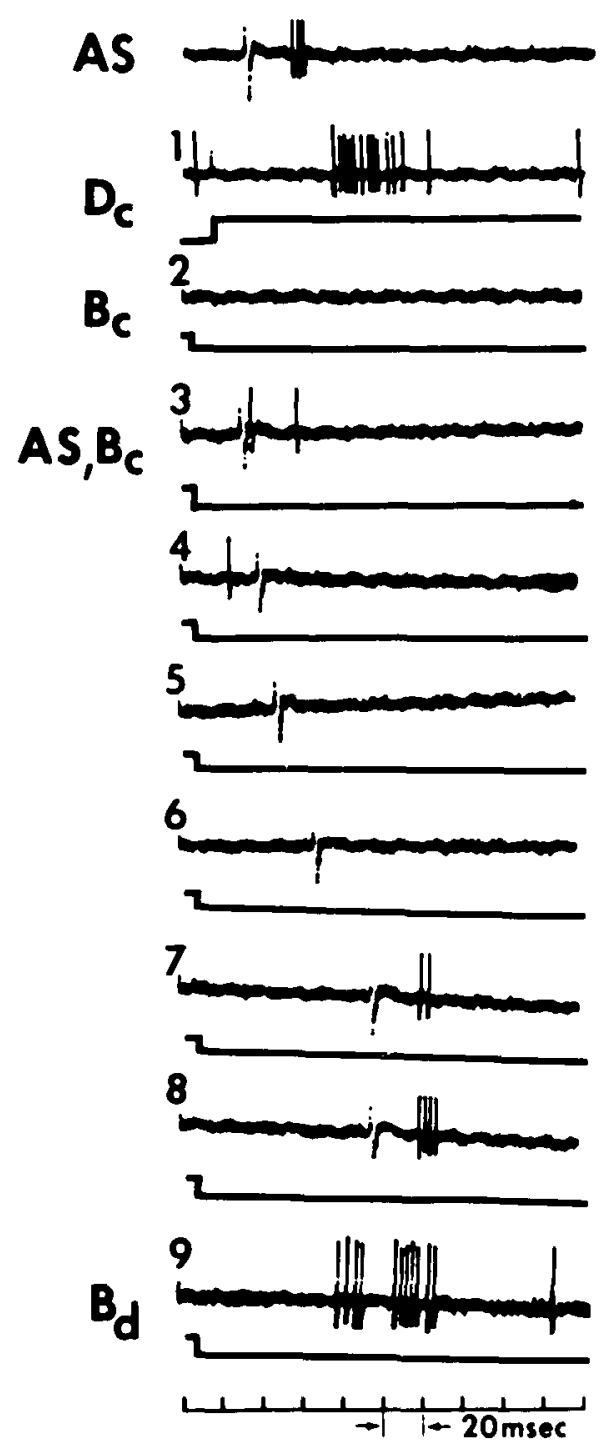

Figure 2 - Inhibition of an OFF-center cell produced by antagonistic spot illumination of the center, i.e. light ON. In A Tracing AS: Control anodal response. Tracing 1: Central dimming (Dc) response. Tracing 2: Central brightening, no response. Tracings 3-8: Pairing of anodal stimulus (AS) with center brightening $(B c)$. The response to AS is suppressed after a 50 msec latency and begins to recover at $115 \mathrm{msec}$. 
D) Inhibition with two spots positioned at the center and in the surround

Appropriate spot (or annular) stimulation of the surround of $\mathrm{ON}$ or OFF- center cells elicited excitatory activity with a characteristic long latent period approximately twice as long as that of excitatory
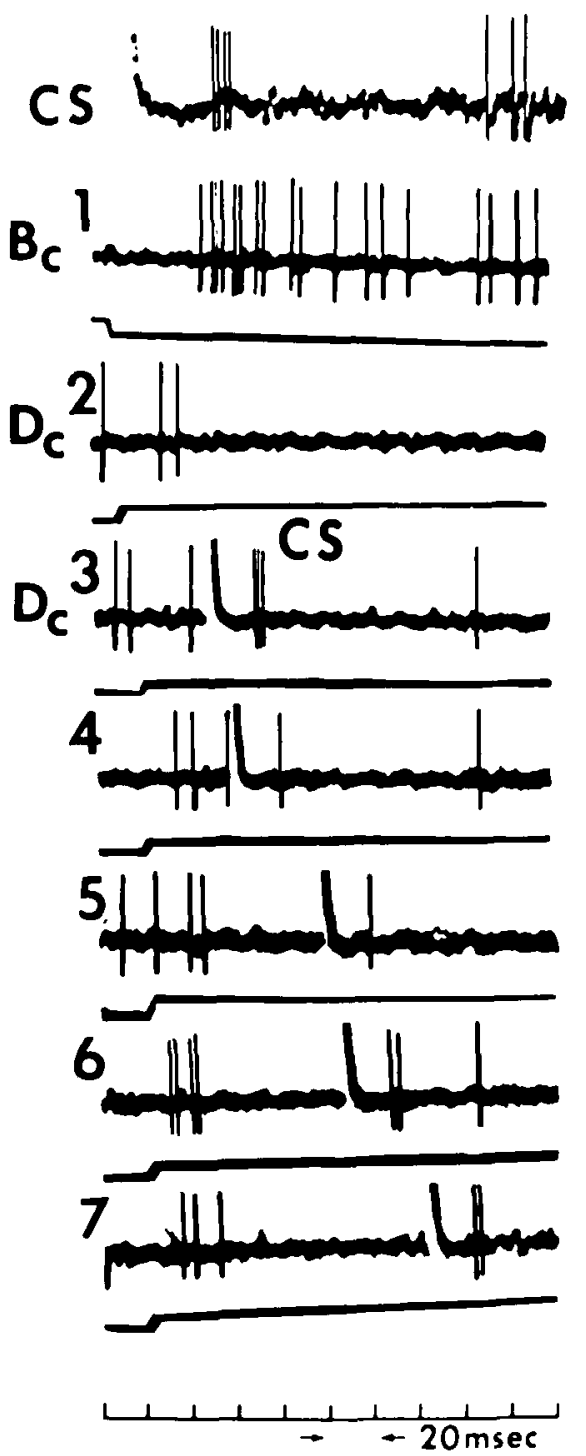

Figure 3 - Inhibition of an ON-center cell produced by antagonistic spot dimming $\left(1^{\circ}\right)$ of the center, i.e. light OFF. Tracings 1 and 2: Response to center brightening $(\mathrm{Bc})$ only. Tracings 3-7: Pairing of the burst produced by the cathodal stimulus (CS) with center dimming ( $\left.D_{c}\right)$ results in the diminution of the cathodal response. The inhibitory period begins at about $45 \mathrm{msec}$ after dimming and lasts up to about $180 \mathrm{msec}$. CS: Control response to cathodal pulse. Spot diameter $1^{\circ}$. response from center stimulation of the same cell. Allen (1969) showed that the long latency responses evoked by electrical pulses were in fact preceded by an inhibitory period of shorter latency. By analogy, therefore, it is possible that the long latency preceding the excitation from photic surround stimulation is conditioned by an inhibitory period of shorter latency. However, when transretinal electrical pulses were used in an attempt to demonstrate inhibition during the long latent period, a negative result was obtained. This is illustrated in Fig. 4. A spot of $1^{\circ}$ in diameter was applied upon the most sensitive area of the surround of that OFF-center unit. The dimming of the surround (Ds) did not evoke a response (tracing 1) while brightening it (Bs) elicited a response (tracing 2 ) in the form of a "broken up" burst of 7-9 spikes with a long latency of $80 \mathrm{msec}$. Tracings 3 and 4 show that the electrical response falling $50 \mathrm{msec}$ after "ON" had the same number of spikes as the controls. This was the case throughout the latent period. The number of spikes varied irregularly between 2 and 3 (Fig. 4, 3 \& 4). These traces were chosen in order to illustrate (cf. trace 5) that in contrast to surround excitation alone, transretinal responsiveness is abolished at the same time after Ds, when Bs coincided with spot brightening of the center (Bc) (Fig. 4, 5). Thus, Fig. 4 shows that in the $50-75$ msec delay before excitation of the surround mechanism caused firing, the electrical stimulus was able to produce its characteristic discharge burst. That the burst was still capable of being suppressed is shown in trace 5 where the center and its surround were stimulated simultaneously, and at such a strength that the surround still produced a discharge. From what has been said above, it is evident that in the period $45-75 \mathrm{msec}$ stimulation of the center would be expected to cause inhibition. And, as seen in trace 5 , the response to anodal stimulation was effectively suppressed. Thus, the absence of any "pre-excitatory inhibition" from the surround mechanism alone is demonstrated.
E) Post excitatory inhibition from the center excitation

In the preceding section it has been shown that the non-excitatory stimuli applied within the center of ON- and OFF-center receptive fields was modified by a reduction of the activity elicited by electrical polarization of the retina. The following section is intended to show an inhibitory phase which superseded the transient discharge evoked by the excitatory stimulus, i.e. ON in ONcenter cells and OFF in OFF-center cells. An example of the post excitatory inhibition is shown in Fig. 5. This example illustrates, for an

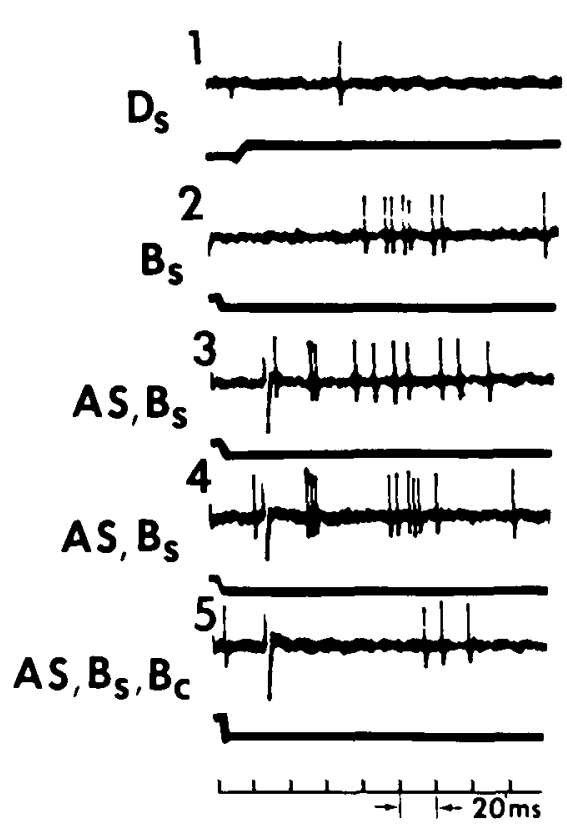

Figure 4 - Inhibition in an Off-center cell in response to simultaneous brightening of center and surround as determined by a paired anodal pulse. Tracing 1: Control dimming of the surround (Ds); no response. Tracing 2: Control brightening of the surround (Bs); long-latency $\mathrm{ON}$-response followed by a silent period. Tracings 3 and 4: Pairing of anodal pulse (AS) with surround brightening (Bs); no distinguishable change in responses to electrical stimulation. Tracing 5 . Combination of anodal pulse (AS), surround brightening (Bs), and center brightening $(\mathrm{Bc})$ resulting in the abolition of the response to AS and a decrease in the response to $\left(\mathrm{B}_{s}\right)$. This suggests that the inhibition is primarily dependent on the center stimulation. (Center and surround spot diameter, $1^{\circ}$ separated by $4^{\circ}$ and of equal intensity against a dark background). 
OFF-center cell, the disappearance of the anodal test response during the silent period following the primary excitatory activity. Upon a dimming stimulus to the center (Dc) (Trace 1) of the receptive field, the cell responded with a short latency burst of about 20 impulses, which was followed by an impulse free period of $70 \mathrm{msec}$. This silent period was terminated by the recurrence of firing at a relatively moderate rate, 5 to 3 spikes. Inhibition was tested by the burst of firing from an anodal (AS) transretinal pulse. As shown in tracings $2,3,4$, the response to the anodal pulse (AS) was abolished when it was combined with the dimming stimulus in such a way that the test burst coincided with the silent period. The tracing 5 (Fig. 5) shows the control response to the anodal pulse.

The same results were obtained in all units tested and in various combinations of dual stimulation such as pairing (within proper delays), dimming the center with brightening of the surround and vice-versa. Additional information on the time course and strength of the post-excitatory inhibition was obtained by varying the size of the central spot as well as the strength of the electrical pulse (Molotchnikoff, 1972). All results showed that following an excitatory phase the responsivity to a test stimulus was reduced or completely abolished.

A refractory state is unlikely to cause this decrease in responsivity. The length of this silent period extended up to $80 \mathrm{msec}$. This is incompatible with a refractory period, the duration of which is usually several milliseconds (Eccles, 1957). Furthermore, ganglion cells were capable of responding to an antidromic shock in similar experimental conditions (Allen, 1969). Since the photic stimulus was always restricted to the center, it is unlikely that this postexcitatory inhibition results from a center-surround interaction. Rather, it seems that it is a consequence of the elicited excitatory activity.

F) Post-excitatory inhibition from the surround excitation

In Fig. 4 the absence of inhibition during the long latent period of the excitatory response from a surround has been shown. However, the long latency excitation was followed by inhibition as shown in Fig. 6 in an $\mathrm{ON}$-center unit. In part A of Fig. 6, the anodal pulse preceded the excitation of dimming in the surround $\left(D_{s}\right)$. One can see that the anodal pulse was unaffected (Tracing 3 and 4). The same number of spikes, i.e. 3 , occurred as in the control response (Tracing 5). However, when the anodal responses coincided with the silent period following the excitatory burst from surround stimulation (Tracings 6 to 10 , Fig. 6), the test response was virtually abolished as soon as the silent period started. In Tracings 7-8 only one spike remained. In support of the statement that post-excitatory inhibition seemed to be dependent upon the excitatory activity, tracing 10, Fig. 6 , shows the poor development of the spike-free period following excitation when, by chance occurrence, the excitatory response was weak.

\section{DISCUSSION}

In this study, the response of a ganglion cell to a brief transitional electrical pulse was used to estimate the degree of inhibition of that cell during the evolving pattern of its response. This test was developed by Crapper and Noell, (1963) \& Allen, (1969). These authors and others (Naka, 1971) concluded that transretinal current pulses act by polarizing the pre-synaptic endings of the receptor cells. This conclusion is supported by some results of the present paper. In OFF-center cells (Fig. 1), the cathodal pulse and the light OFF stimuli both evoked responses of shorter latency than the anodal and light $\mathrm{ON}$ stimulus respectively. In ON-center cells (Fig. 1) the converse situation holds. The anodal and light $O N$ stimuli produced responses of shorter latency than the opposite stimuli. Thus, the anodal pulse appeared to mimic the effect of a brightening stimulus for OFF- as well as ON-center cells, whereas the cathodal pulse had the same effect as a dimming stimulus. The basic assumption for the use of a transretinal pulse as a test of an inhibitory state is that a pulse of fixed magnitude produces a constant change in the pre-synaptic membrane regardless of whether the receptor is receiving light at the time as the pulse is applied. One of the important features of the transretinal pulse tests is that inhibitory pauses can be identified. These may evolve during the silent period in the ganglion cell response to a light stimulus. For example, an OFF-center (Fig. 2) unit which does not fire when the center is stimulated by light $O N$, nevertheless has a period of inhibition which evolves during this silent period. Thus, the use of the electrical stimulation as a test for inhibition gives information
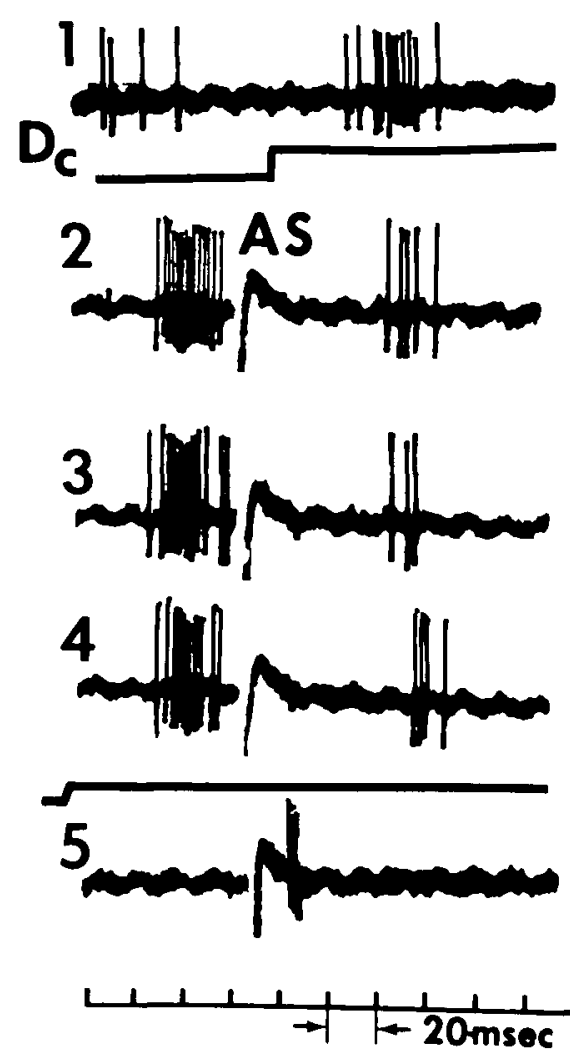

Figure 5 - Post-excitatory inhibition from the center excitation in OFF. center cell. (Dc) control response to a dimming stimulus applied within the center. Tracings 2-3-4 pairing of the anodal pulses (AS) with the center dimming. No responses is elicited by AS during the inhibitory period following the initial discharge in response to Dc. Tracing 5 control response to anodal pulse AS. Spot diameter $1^{\circ}$. Note that on Tracing 1 the dimming (OFF) stimulus is applied at the middle of the screen, on Tracings 2, 3, 4 the OFF stimulus is delayed at the beginning of the sweep. 
that could not be obtained by simple observation of the cell's firing rate following light stimulus.

Two types of stimulation elicited inhibitory periods of short latency (40 to $50 \mathrm{msec}$ ). For OFF-center cells it was spot brightening (Fig. 2). For ON-center cells, it was spot dimming (Fig. 3). This inhibition was not associated with impulse activity and was specific to the antagonistic photic stimuli (Fig. 4). This type of inhibition may be identified as "primary inhibition" since it occurs with short latency and it is the primary effect of the non-excitatory stimuli. Analogue results were demonstrated by using dual spot stimulation positioned within the centre
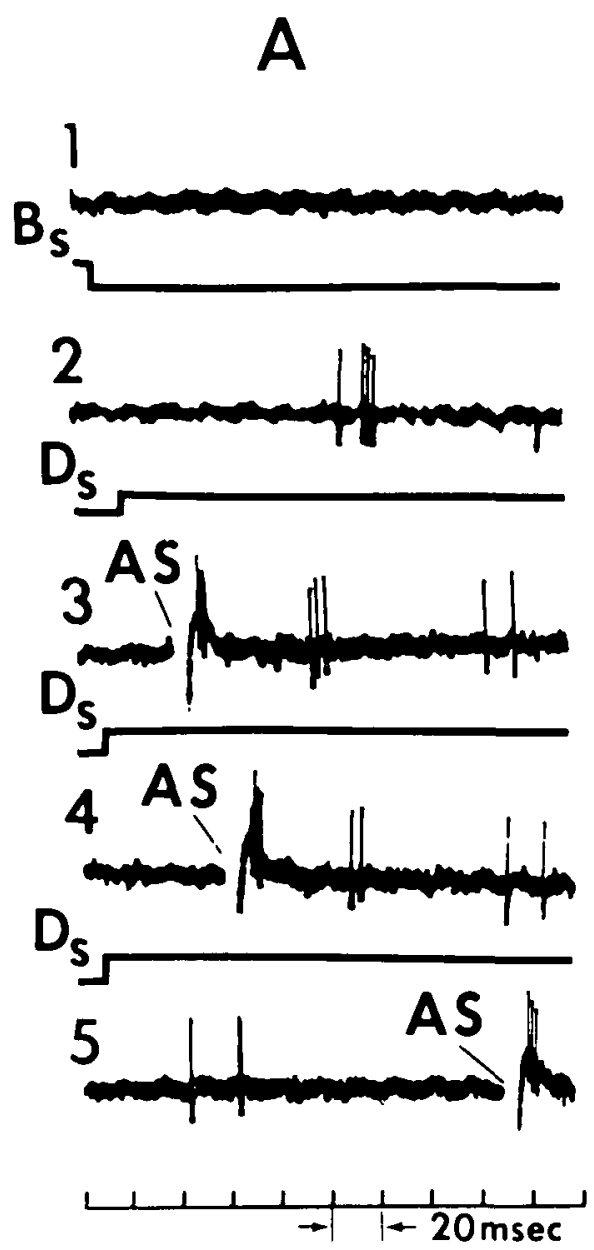

and the surround, (Barlow, 1953Levick, 1967; Rodieck, 1965; Molotchnikoff, 1972) and it has been shown that both central and surround "ON" and "OFF" responses were reduced or abolished. Thus, the responses to transretinal stimulation behaved as light evoked responses.

For the cat, it has been suggested that when the overlapping antagonistic mechanisms of the center and the surround have the same time course, then the surround response is delayed (Rodieck, 1965; Enroth-Cugell and Pinto, 1972a, b).

However, Fig. 4 shows that in the rabbit the long latency discharge from surround excitation is not pre-
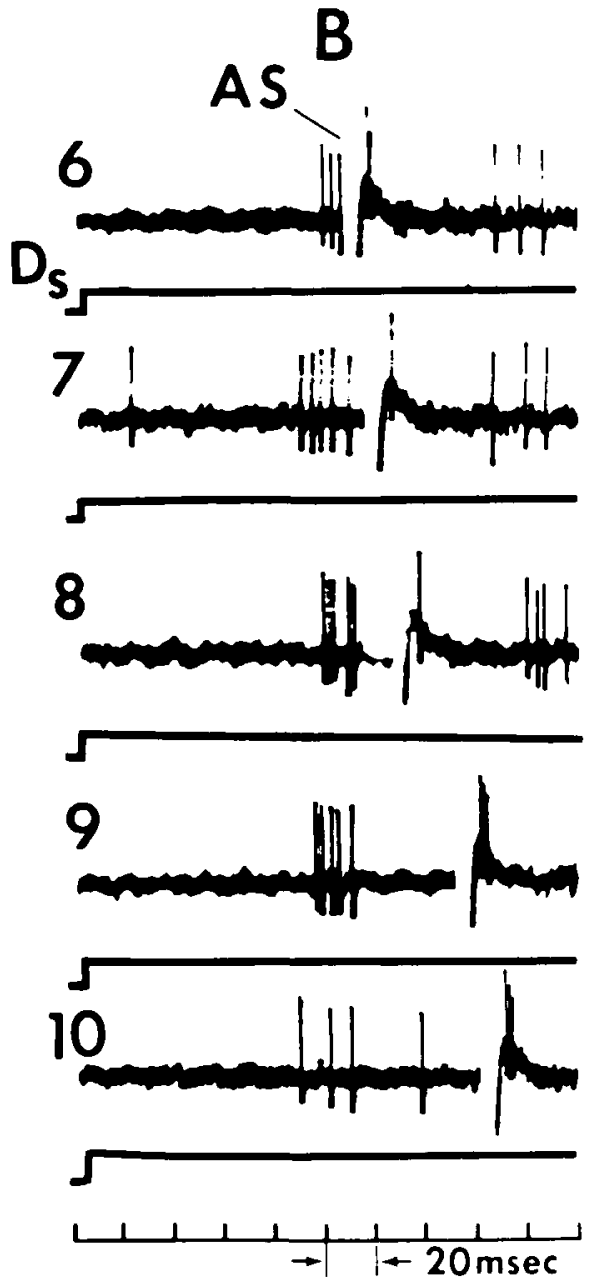

Figure 6 - Inhibition in an ON-center cell following spot dimming of surround as determined by paired, anodal transretinal stimuli. Column A: Anodal pulse (AS) preceding OFF-discharge. Tracing $\mathrm{I}$ : control brightening of surround (Bs); no response. 2: control dimming of surround (Ds): OFF-response. 3 and 4: anodal pulse (AS) preceding OFF-response to surround dimming (Ds); anticipated anodal response. Column B. Anodal pulse falls after the OFF-discharge. Note the anodal burst reduced in Tracings $6,7,8$. ceded by a period of diminished responsiveness to the electrical pulse. One can argue that a spot is not an optimal stimulus to produce surround effects, consequently the inhibition if present would be too weak to suppress firing evoked by electrical activation of the retina. However, the same spot positioned in the surround and evoking a response of the same strength would produce an inhibition of the response evoked by the electrical stimulation of the retina if the latter was applied after the photically evoked response (Fig. 6). Hence, it is conceivable that the surround response is not preceded by any inhibitory pause.

Considering that the surround is too large to be a direct bipolar input upon the ganglion cell, this absence of inhibition prior to the surround discharge suggests that the direct input to the ganglion cell is not primarily affected by the excitatory surround stimulus. It seems possible that surround excitation is different from that of the direct center input. Most probably the surround discharge is generated indirectly through channels which connect to the ganglion cell within the inner plexiform layer through amacrine cell, serial synapses. The surround discharge could be conveyed through feed-forward and lateral synapses of the amacrine process (Dubin, 1970; Dowling and Werblin, 1971; Dowling and Boycott, 1965).

An inhibitory period always followed an excitatory activity. This second or post excitatory inhibition can be distinguished from primary inhibition. The secondary inhibition was not specific to the spatial location of the stimulating spot as was the case for primary inhibition. The post-excitatory inhibition was revealed whenever the excitation has occurred, and was thus associated with impulse activity (Fig. 4 and 5). The secondary inhibition followed center excitation at a time when primary inhibition was decaying or had ended. For example, in Fig. 2, the release of inhibition coincided approximately with the occurrence of the "ON" discharge (Tracing 9) evoked by diffuse brightening. This response was superseded by a post- 
excitatory inhibition. The feed-back synapses of the amacrine cells onto bipolar units could account for this post-excitatory inhibition (Raviola and Raviola, 1967; Werblin and Dowling, 1969)

\section{ACKNOWLEDGEMENT}

I am indebted to W. K. Noell for constant support and advice during the course of this work. I also thank W. V. Walker for his technical assistance and $A$. Laperrière for typing the manuscript.

\section{REFERENCES}

ALLEN, G. I. (1969). Excitability properties of large ganglion cells in the rabbit retina. Ph.D. dissertation, State Univ. N. Y. at Buffalo.

BARLOW, H. B. (1953). Summation and inhibition in frog's retina. Journal of Physiology 119: 69-88.

BARLOW, H. B., HILL, R. N. and LEVICK, W. R. (1964). Retinal ganglion cells responding selectively to direction and speed of image motion in the Rabbit. Journal of Physiology 173: 377-407.

BARLOW, H. B. and LEVICK, W. R. (1965). The mechanism of directionally selective units in Rabbit's retina. Journal of physiology 178: 477-504.

CRAPPER, D. R. and NOELL, W. K. (1963). Retinal excitation and inhibition from direct electrical stimulation. Journal Neurophysiology 26: 924-947.
DOWLING, J. E. and WERBLIN, F. (1971). Organization of retina of the vertebrate retina. Vision Research Supp. 3: 1-15

DOWLING, J. E. and BOYCOTT, B. B. (1965). Neural connections of the retina: fine structure of the inner plexiform layer. Cold Spring Harbor Symp. Quant Biol. 30: 939-402

DUBIN, W. (1970). The Inner plexiform layer of the vertebrate retina: A quantitative and comparative electron microscopic analysis. Journal of Comparative Neurology 140: 479-505.

ECCLES, J. C. (1957). The physiology of nerve cells. Baltimore, Johns Hopkins Press

ENROTH-CUGELL, C. and PINTO, L. H. (1972a). Properties of the surround response mechanism of cat retinal ganglion cells and centre-surround interaction. Journal of Physiology 220: 403-439.

ENROTH-CUGELL, C. and PINTO, L. H. (1972b). Pure central responses from OFFcentre cells and pure surround response from ON-centre cells. Journal of Physiology 220: 441-464.

ENROTH-CUGELL, C. and PINTO, L.H. (1970). Algebraic summation of centre and surround inputs to retinal ganglion cells of the cat. Nature 226: 458-459.

FUKADA, Y. (1971). Receptive field organization of cat optic nerve fibers with special reference to conduction velocity. Vision Research 11: 209-226.

JUNG, R. (1973). Handbook of sensory physiology. Central Processing of visual information Part A. Springer Verlag. Vol. 713.
KUFFLER, S. W. (1953). Discharge patterns and functional organization of mammalian retina. Journal Neurophysiology 16: 37-68.

LEDERMAN, R. J. and NOELL, W. K. (1968). Fast fiber system of rabbit optic nerve. Vision Research 8: 1385-1398.

LEDERMAN, R. J. and NOELL, W. K. (1969). Optic nerve population responses to transretinal electrical stimulation. Vision Research 9: 1041-1052.

LEVICK, W. R. (1967). Receptive fields and trigger features of ganglion cells in the visual streak of the rabbit's retina. Journal of Physiology 188: 285-307.

MOLOTCHNIKOFF, S. (1972). Analysis of receptive field antagonistic function in rabbit retina by light and electrical stimuli. $\mathrm{Ph}$. D. Dissertation, State Univ. N.Y., Buffalo.

NAKA, K. I. (1971). Receptive Field Mechanism in the Vertebrate Retina. Science 171: 691-696.

RAVIOLA, G. and RAVIOLA, E. (1967). Light and electron microscopic observations on the inner plexiform layer of the rabbit retina. American Journal of Anatomy 120: 403-426.

RODIECK, R. W. (1965). Quantitative analysis of cat retinal ganglion cell response to visual stimuli. Vision Research 5: 583-601.

RODIECK, R. W. and STONE, J. (1965). Analysis of receptive fields of cat retinal ganglion cells. Journal of Neurophysiology 28: 833-849.

WERBLIN, F. S. and DOWLING, J. E. (1969). Organization of the retina of the mud-puppy Necturus maculosus II. Intracellular recording Journal of Neurophysiology 32: 339-355. 